\title{
FOURIER MULTIPLIERS ASSOCIATED WITH SINGULAR PARTIAL DIFFERENTIAL OPERATORS
}

\author{
C. BACCAR, N. Ben HAMAdi AND S. OMRI
}

Abstract. We prove the Hörmander-Mikhlin multiplier theorem for the Fourier transform associated with the Riemann-Liouville operator.

Mathematics subject classification (2010): 43A32, 42B10.

Keywords and phrases: Riemann-Liouville operator, Fourier transform, Bernstein inequality, Fourier multipliers, Hörmander-Mikhlin theorem.

\section{REFERENCES}

[1] L. E. Andersson, On the determination of a function from spherical averages, SIAM. J. Math. Anal., 19: 214-234, 1988.

[2] G. E. Andrews, R. Askey, And R. Roy, Special functions, volume 71, Cambridge university press, 1999.

[3] C. BAccar, N. B. Hamadi, H. Herch, AND F. Meherzi, Inversion of the Riemann-Liouville operator and its dual using wavelets, Opuscula Math., 35 (6): 867-887, 2015.

[4] C. BACCAR, N. B. HAMADI, AND L. T. RAChDI, Inversion formulas for the Riemann-Liouville transform and its dual associated with singular partial differential operators, Int. J. Math. Math. Sci., 2006: 1-26, 2006.

[5] C. BACCAR, N. B. HAMADI, AND L. T. RACHDI, Best approximation for Weierstrass transform connected with Riemann-Liouville operator, Commun. Math. Anal., 5 (1), 2008.

[6] C. BACCAR AND L. RACHDI, Spaces of DL ${ }^{p}$-type and a convolution product associated with the Riemann-Liouville operator, Bull. Math. Anal. Appl., 1 (3): 16-41, 2009.

[7] W. R. Bloom And Z. XU, Fourier multipliers for $L^{p}$ on Chébli-Trimèche hypergroups, Proc. London Math. Soc., 80 (03): 643-664, 2000.

[8] R. COIFMAN AND G. WeISs, Analyse harmonique non-commutative sur certains espaces homogènes, Lecture Notes in Math., 242: 569-645, 1977.

[9] J. A. FAWCETT, Inversion of $N$-dimensional spherical averages, SIAM J. Appl. Math., 45 (2): 336$341,1985$.

[10] V. Fischer And M. RuZhansky, Quantization on nilpotent Lie groups, Progress in Mathematics, volume 314, Birkhauser, 2016.

[11] J. Gosselin And K. Stempak, A weak-type estimate for Fourier-Bessel multipliers, Proc. Amer. Math. Sec., 106 (3): 655-662, 1989.

[12] L. Grafakos, Classical Fourier Analysis, volume 2, Springer, 2008.

[13] N. B. HAMADI, Generalized homogeneous Besov spaces associated with the Riemann-Liouville operator, Internat. J. Math., 26 (02): 21, 2015.

[14] N. B. HAMADI AND L. RACHDI, Fock spaces and associated operators for singular partial differential operators, Int. J. Math. Anal., 1 (18): 873-895, 2007.

[15] N. B. HAMADI AND L. T. RACHDI, Weyl transforms associated with the Riemann-Liouville operator, Int. J. Math. Math. Sci., 2006, 2006.

[16] H. Hellsten And L.-E. Andersson, An inverse method for the processing of synthetic aperture radar data, Inverse problems, 3 (1): 111, 1987.

[17] M. HERBERTHSON, A numerical implementation of an inverse formula for carabas raw data, National Defense Research Institute, Internal Report D, pages 303-304, 1986. 
[18] L. Hörmander, Estimates for translation invariant operators in $L^{p}$ spaces, Acta Math., 104 (1): 93-140, 1960.

[19] R. KAPELKo, A multiplier theorem for the Hankel transform, Rev. Mat. Complut., 11 (2): 281-288, 1998.

[20] N. N. LeBedEV, Special functions and their applications, Courier Corporation, 1972.

[21] S. G. MikhLin, The multipliers of Fourier integrals, Dokl. Akad. Naulc SSSR (N. S.), 109 (4): $701-$ $703,1956$.

[22] S. OMRI AND L. RACHDI, Heisenberg-Pauli-Weyl uncertainty principle for the Riemann-Liouville operator, J. Inequal. Pure Appl. Math, 9 (3): 1-23, 2008.

[23] M. RuZhans Ky, M. Vladimirovich And J. Wirth, On multipliers on compact Lie groups, Funct. Anal. Appl, 47 (1): 72-75, 2013.

[24] M. RUZHANSKY AND J. WiRTh, Lp Fourier multipliers on compact Lie groups, Math. Z, 280: 621$642,2015$.

[25] E. M. STEIN, Singular integrals and differentiability properties of functions, volume 2, Princeton university press, 1970. 